\title{
21. Yüzyılda Deneysel Kamusal Sanat
}

\author{
Cemre Kılınç 1 \\ ORCID: 0000-0001-8651-6945
}

\author{
Osman Tutal ${ }^{2}$ \\ ORCID: 0000-0003-1454-5514
}

Öz

21. yüzyılla birlikte değişen sosyal çevre, kamusal sanata olan ilgiyi artırmış ve sanat, toplumsal bir ihtiyaca dönüşmüştür. Kamusal alandaki sanatsal faaliyetler çeşitlendikçe sanat, kamusal alanın vazgeçilmez bir parçası olmaya başlamıştır. 2000'li yıllardan bu yana hem süreç hem de sonuç odaklı kamusal sanat faaliyetleri pavyon ve enstalasyon gibi deneysel çalışmalarla yeni bir ivme kazanmış ve bu durum kamusal sanatı başka bir noktaya getirmiştir. Öyle ki bu farklılaşma sanatla/sanat ürünü ile olan etkileşime de yansımış ve gelişen teknoloji ile birlikte fiziki erişim dışında kamusal faaliyetlere yeni erişim şekilleri ortaya çıkmış ve kısa sürede yaygınlaşmıştır. Bu çalışma, 21. yüzyılda paoyon-enstalasyon gibi disiplinler arası deneysel kamusal sanat ürünlerinin sayılarının artmasıyla ortaya çıkan biçimsel, işlevsel ve uygulama alanındaki benzerliklerini ve bu doğrultuda giderek tek tipleşmelerini örnekler üzerinden tablolar aracıllğıla ele alarak, sanatın deneyselliğini sorgulamakta ve içinde bulunduğumuz Covid-19 salgımı döneminde kamusal sanatın nasıl bir dönüşüm yaşadı̆̆ını tartışmaktadır. Bu doğrultuda 21. yüzyılda, çoğu kamusal sanat ürününün özgün olamaması ve kendini tekrar etmesinin kamusal sanat ile deneysellik arasına mesafe koyduğu sonucuna varılmıştır. Covid-19 salgın sürecinde ise sosyal mesafeden ötürü herhangi bir bağlama ait olamayan sanatın, dijital sanata kayma halinin tıpkı salgından önceki deneysel kamusal sanatın tek tipleşmesi süreci gibi bu dönemi de tek tipleştirebileceğgi düşünülmektedir.

Anahtar Kelimeler: kamusal sanat, deneysellik, deneysel kamusal sanat, covid-19

\footnotetext{
1 Öğretim Görevlisi, Bingöl Üniversitesi, E-mail: ckilinc@bingol.edu.tr

2 Prof. Dr., Eskişehir Teknik Üniversitesi, E-mail: otutal@eskisehir.edu.tr

idealkent @ C Kent Araştırmaları Dergisi (Journal of Urban Studies) 


\title{
Experimental Public Art in the 21st Century
}

\author{
Cemre Kulınç 3 \\ ORCID: 0000-0001-8651-6945
}

\author{
Osman Tutal ${ }^{4}$ \\ ORCID: 0000-0003-1454-5514
}

\begin{abstract}
The changing social environment with the 21st century has increased the interest in public art and art has turned into a social need. Since the 2000s, both process and result-oriented public art activities have gained a new momentum with experimental works such as pavilions and installations. So much so that this differentiation is reflected in the interaction with art/art product. This study examines the experimentalism of art by examining the similarities in the formal, functional and application fields that emerged with the increase in the number of interdisciplinary experimental public art products such as the pavilion-installation in the 21st century, and their increasingly uniformity in this direction, through examples, and questions the experimentalism of art. Discusses the transformation of public art during the Covid-19 pandemic. In this direction, it has been concluded that in the 21st century, the inauthenticity and repetition of most public art products distances itself between public art and experimentation. In the Covid-19 pandemic process, it is thought that the shift of art, which cannot belong to any context due to social distance, to digital art, can standardize this period, just like the standardization process of experimental public art before the pandemic.
\end{abstract}

Keywords: public art, experimentality, experimental public art, covid-19

\footnotetext{
${ }^{3}$ Instructure, Bingöl University, E-mail: ckilinc@bingol.edu.tr

${ }^{4}$ Prof. Dr., Eskişehir Teknik University, E-mail: otutal@eskisehir.edu.tr

idealkent @ Kent Araştırmaları Dergisi (Journal of Urban Studies) 


\section{Giriş}

Toplumun her kesiminin ortak bir paydada buluştuğu sahne olarak adland1rılabilecek olan kentsel mekânlar bu özelliğiyle tarih boyunca toplulukları toparlayıcı bir unsur olmuştur. Kentsel mekânlardaki yaşama ev sahipliği yapan ve kentin okunabilirliğine katkı sağlayan kamusal alanlar kendine özgü tarihsel, kültürel ya da coğrafik özellikler ve karakteristiklerle kentleri yaşanılır kılan en önemli ögelerdendir. Kamusal alan "Özel şahısların, kendilerini ilgilendiren ortak bir konu üzerinde akıl yürüttükleri, rasyonel bir tartısma içine girdikleri ve bu tartışmanın neticesinde o mesele hakkında ortak kanaati, kamuoyunu oluşturdukları araç, süreç ve mekânların tanımladığı hayat alanı Habermas (1962)" olarak tanımlanmaktadır. Aydın (2015) kamusal alanı "Toplumun ortak yararını belirlemeye ve gerçekleştirmeye yönelik düşünce, söylem ve eylemlerin üretildiği ve geliştirildiği ortak toplumsal etkinlik alanı." şeklinde ifade etmiştir. Kamusal alan bireylerin bir araya gelerek uyum içinde hareket ettikleri, farklılıklarını açığa çıkardıkları, kendilerini özgür hissettikleri etkileşim mekânıdır (Kejanlığlu, 2004) (Yılmaz, 2007) (Yükselbaba, 2011). Sheikh (2007)'ye göre kamusal alan birbirinden keskin sinurlarla ayrılmak yerine muğlak sınırlar çerçevesinde, deneyime dayandırılarak incelenmelidir. Bu muğlak sınırları oluşturan en önemli etmenler ise kamusal alanlarda farklı disiplinleri içinde barındırarak üretilen oluşumlardır. Kentlerin belleğinde önemli bir yer tutan bu oluşumlar kamusal alanlardaki kamusal sanat fikrinden geçmektedir (Mitrache, 2012). Bu çalışmanın amacı bir kent sahnesi olarak kamusal alanların 21. Yüzyıl kapsamında disiplinler arası deneysel kamusal sanat ürünlerinin sayılarının artmasıyla benzerliklerinin de artması, tek tipleşmeye doğru ilerleyen bu sürecini sanatın deneyselliği üzerinden sorgulamak ve içinde bulunulan Covid-19 salgın döneminde kamusal sanatın nasıl bir dönüşüm yaşadığını tartışmaktadır. Çalışmada nitel araştırma yöntemi kullanılmıştır. Betimsel inceleme yapılmış ve veriler nitel veri araçlarından döküman inceleme yoluyla elde edilmiştir. Döküman inceleme kamusal sanat, deneysel sanat ve Covid-19 salgın sürecinde sanatla ilgili olarak görseller, yorumlar, değerlendirme yazıları, makaleler üzerinden yapılmıştır.

\section{Yüzyılda Kamusal Sanat}

Kamusal sanat en yalın haliyle toplumun rahatlıkla görebileceği, ulaşılabilir ve genelde kamusal mekânda yapılan sanat olarak tanımlanabilir (Hayden, 1995). "Pratik hatta mekanik bir yeteneğin, yaratıcılıkla yoğrulup ortaya sıra dışı bir eser halinde dökülmesi ve kişinin bireysel olarak içindekileri ruh, zekâ, 
duygu ve beden harmonisiyle dişarıya yansıtması (Aydın, 2015)" şeklinde tanımlanan sanatın kamusal mekândaki icrası, onu bireysellikten çıkararak toplumun deneyimlemeye başladığı bir platforma dönüştürür. Bu platformda sunulan deneyim ise her bireyin kendine göre anlamlandıracağı bir süreci temsil eder. Gündelik hayatta bireyin alışageldiği kamusal bir mekânı yeniden tanımlama gücüne sahip olan kamusal sanat, bireye kendi deneyimi süresince kanısadığı mekâna yeni keşifler ve yeni algılar geliştirme fırsatını da sunar.

Avangard akım ile başlayıp günümüze kadar evrilerek gelen kamusal sanatın farklı pratik ve disiplinlerle olan iş birliği, sınırlarını muğlaklaştırarak ona deneysel bir özellik kazandırmaktadır. Disiplinlerin ortak bir paydada buluşmaları ilk olarak 20. yüzyılda, sanatın nesne statüsünden çıkıp sınırlarının ötesine geçerek kamusal alana dahil olmasıyla başlamıştır. Geleneksel olanın sorgulanmaya başlandığı bu süreçte teknolojinin ilerlemesiyle gelişen araçlar sanatta yeni ifadeler ve yeni bakış açları yaratmıştır. 'Beyaz küp' olarak adlandırılan sanatın kendi içine kapandığı müze, galerilerdeki elitist tavrı sanatta klasik geleneğin temsil metotlarındaki nesnenin doğrudan resmedilmesine karşı gelmiş ve sanatçıları yeni arayışlara yönlendirmiştir. 20. Yüzyılın ilk yarısında hakimiyet kurmuş olan ‘Beyaz küp'te birey genellikle sanat ürününü izleyip nadiren deneyimlerken kamusal mekânda birey hem sanat ürününü deneyimler hem de sanat ürünü bulunduğu kamusal mekânı deneyimleme firsatı yakalamış olur. 20. Yüzyılın ikinci yarısı ile sanat alışkanlıklarından sıyrılarak günlük yaşama, kamusal mekâna dahil olmaya başlamıştır. Geçici süreyle sergilenen kamusal sanat ürünleri kentsel alanların ve kentlilerin belleklerini şüphesiz kalıcı yapılardan daha fazla şekillendirmiştir. Kamusal mekandaki kamusal sanat ürünü o mekânı bilen birey için sürpriz olma özelliği taşımış, bu sayede birey kanıksadığı mekâna ayrı bir gözle bakarak o mekânı sanat ürünüyle deneyimleme fırsatını yakalamıştır (Kılınç, 2020). Dolayısıyla kamusal mekâna yeni bir soluk olup, sosyal ilişkilere zemin hazırlayan deneysel kamusal sanat ürünleri, döneme dinamizm katarak süreci başkalaştırmıştır.

21. Yüzyıla gelindiğinde gelişen teknoloji sayesinde kamusal mekândaki geçici sanatsal faaliyetler çeşitlenerek kamusal mekânın vazgeçilmezi olmaya başlamıştır. 21. yüzyılda gündelik yaşamda standart kullanımlara sahip mekânlar deneysel sanat ürünleri ile daha dinamik bir etkiye sahip olmuştur. Bu etkinin artmasında şüphesiz 20. Yüzyılda sergilenen deneysel kamusal sanat ürünlerinin katkısı oldukça büyüktür. Günümüzde kamusal sanata olan ilgi giderek artmakta ve kamusal sanat toplumsal bir gereksinime dö- 
nüşmektedir. Sergilenen ürünler kimi zaman belirli bir fonksiyona sahip olabilirken, kimi zaman sadece bir sanat eseri olarak karşımıza çıkmakta ya da her iki özelliği içerisinde barındırabilmektedir (Phillips, 1999). İçinde bulunduğumuz salgın dönemi her ne kadar kamusal mekânın vazgeçilmezlerini değiştirmeye başlamış olsa da bireyin günlük hayatta karşılaştığı geçici kamusal sanat ürünlerinin, kanıksadığı kamusal mekâna yeni bir soluk ve dinamizm getirdiği gerçeğini değiştirmez. 21. Yüzyılda dünyanın çeşitli yerlerinde sergilenen kamusal sanat ürünleri, bireylerin katılımcı rol üstlendiği, deneyim anlamında aktif olarak yer aldıkları, teknolojiyi içinde barındıran ve disiplinlerin iş birliği içerisinde olduğu ve deneysel rol üstlendikleri bir döneme doğru evrilmiştir. Bu anlamda özellikle salgın döneminden öncesine kadar olan süreçte disiplinlerin birbirini besleyerek kamusal sanat aracllı̆̆ıyla bir diyalog oluşturması, deneyin, deneyimin ve deneyselliğin gündelik yaşamda bir ara alan üreterek kamusal alana olan geçici müdahalesi ile mekânı yeniden tanımlaması oldukça önemlidir.

\section{Deneysel Kamusal Sanat Ürünlerinde Benzerlikler}

Kamusal sanat en temelde deneyseldir ve gündelik yaşamda (hem gerçek hem sanal dünyada) iletişimimizin her alanına sızar (Hanru, 2007). Sanatın yeni düşünce ve uygulamaların denendiği bir laboratuvar oluşu ve sürecin deneyimlenebildiği, test edilebildiği bir alan olarak kamusal mekânlarda, 2000'li yıllar itibariyle sıkça görmeye başladığımız disiplinler arası üretimler olan pavyon, enstalasyon gibi deneysel kamusal sanat ürünleri mekâna getirdiği canlılık, dinamizm ve estetikle dikkat çekmektedir. Çoğunlukla bizzat yerinde görülemiyor olsa da hemen her gün makalelerde, dergilerde, internet sitelerinde, mimari medya ya da sosyal medyada enstalasyon, pavyon gibi deneysel kamusal sanat ürünlerinin sergilendiği haberleri görülmektedir. 21. Yüzyıl ile kamusal sanatın hayatlarımızda daha çok yer edinmesi ve dünyanın farklı coğrafik bölgelerinde, kentlerinde sergilenmesi fazlasıyla değerlidir. Bu bakımdan sanatın bireye, kente, mekâna sağladığı pozitif yönler göz ardı edilemez derecededir. Fakat deneysel kamusal sanat ürünlerinin sayılarının bu kadar artması durumu da dikkat çekici olmaya başlamıştır. Öyle ki dünya sahnesinde son yirmi yıldır kendisine oldukça yer bulmaya başlayan bu ürünler "Pavyonlar her yerdedir." (Lavin, 2012) gibi söylemlere de yans1mıştır. Bu 'her yerde' olma durumuyla gelen uygulamaların çoğalması kamusal sanat ürünlerinde benzerliklerin artmasına neden olmuştur. Artan benzerlikler ise, Lavin (2012)'in de ifade ettiği gibi 'muhtemelen deney yap- 
mak için kullanılan' pavyon, enstalasyon gibi kamusal sanat ürünlerinde deney-deneysellik parametrelerinin nerede olduğu sorgulamasını beraberinde getirmektedir. Güzer (2019), mimarlık ile sanatın kurduğu ilişkinin tesadüf olmadığını, tam tersine disiplinin içinde zaruri bir bağlantı olduğu ve mimarlığın sanatı da barındıran en büyük tasarım şemsiyesi olduğunu ifade etmiştir. 21. Yüzyıl ile bu tasarım şemsiyesi altında enstalasyonlar ve pavyonlar şaşırtıc bir biçimde üretilmektedir. Bugün pavyon, enstalasyon gibi ürünlerin bu denli üretilmesinin sebebi ise kamusal sanatın mimarlık ve sanat dalları arasında kalmasından kaynaklanmaktadır (Kılınç, 2020). Mimarlar, tasarımcılar, heykeltıraşlar, sanatçlar ve pek çok disiplinin bir arada olup kaynaşması üretici sınıfını genişletmiştir. İç içe geçen disiplin ve pratiklerdeki üretici nüfusun yeni 'melez' türler üretmesi ile kamusal sanatın sayıca fazlalaşması kaçınılmaz olmuştur (Lavin, 2012). Bugün mevcut koşullar ve sosyal ortamın gelişmişliği bilgiye daha kolay erişimi sağlamakta ve dünyanın çeşitli yerlerindeki insanların günlük olaylara aynı anda hâkim olma durumunu doğurarak sınırsızlık kavramını oluşturmaktadır. Sınırsızlı̆̆ın getirdiği erişim rahatlı̆̆ı, teknolojik zemin ile kamusal sanat şablonlara indirgenerek tek tipleşmeye neden olmaktadır. Böylelikle kamusal sanat ürünleri içeriğin irdelenmeden kabul edildiği bir güncellik kavramı ile karşı karşıya kalmaktadır (Güzer, 2019). Özellikle medya ve sosyal medyada yoğunlukla karşılaşılan benzer özellikteki kamusal sanat uygulamaları 'güncellik' fikriyle 'sanatta olması gereken' intibasını oluşturmakta ve tasarımcıları yönlendirerek kabul görenin bu ürünler olduğu izlenimini uyandırmaktadır. Bu yaklaşım ise, benzer nitelikteki kamusal sanat ürünlerinin tekrarına sebep olmakta, onları "çoğaltılmış prototiplere (Güzer, 2019)" dönüştürmektedir. Bu prototipleşme ise sanatı temelinde barındırdığı deneyci tavrından uzaklaştırmaktadır. Çünkü sanat en temelde geleneksele karşı çıkıp geçmişle arasına çizgi koyarak deneyci bir tavır içerisindedir (Yırtıcı, Gürer ve Yıldız, 1993). Ve bu tavır Hannula (2007) tarafından deneyin tekrarlanabilir ancak deneysel olanin tekrarlanamaz olduğu ve deneysel olanın "özel ve biricik" olması gerektiği şeklinde yorumlanmıştır. Dolayısıyla bu ifadeler günümüzde kamusal sanattaki tek tipleşmenin kamusal sanatın deneyselliğiyle olan ilişkisine dair sorgulamayı da beraberinde getirmektedir. Bu bağlamda 21. Yüzyıl ile biçimsel, işlevsel ve uygulama alanında benzerlikleri bulunan bazı kamusal sanat ürünleri aşağıdaki görsellerde tablolaştırılarak deneysellikle olan ilişkileri sorgulamaya açlmıştır. 
Tablo 1. Deneysel Kamusal Sanat Ürünlerinde Biçimsel Benzerlikler (Kılınç, 2020'den uyarlanmıștır.)

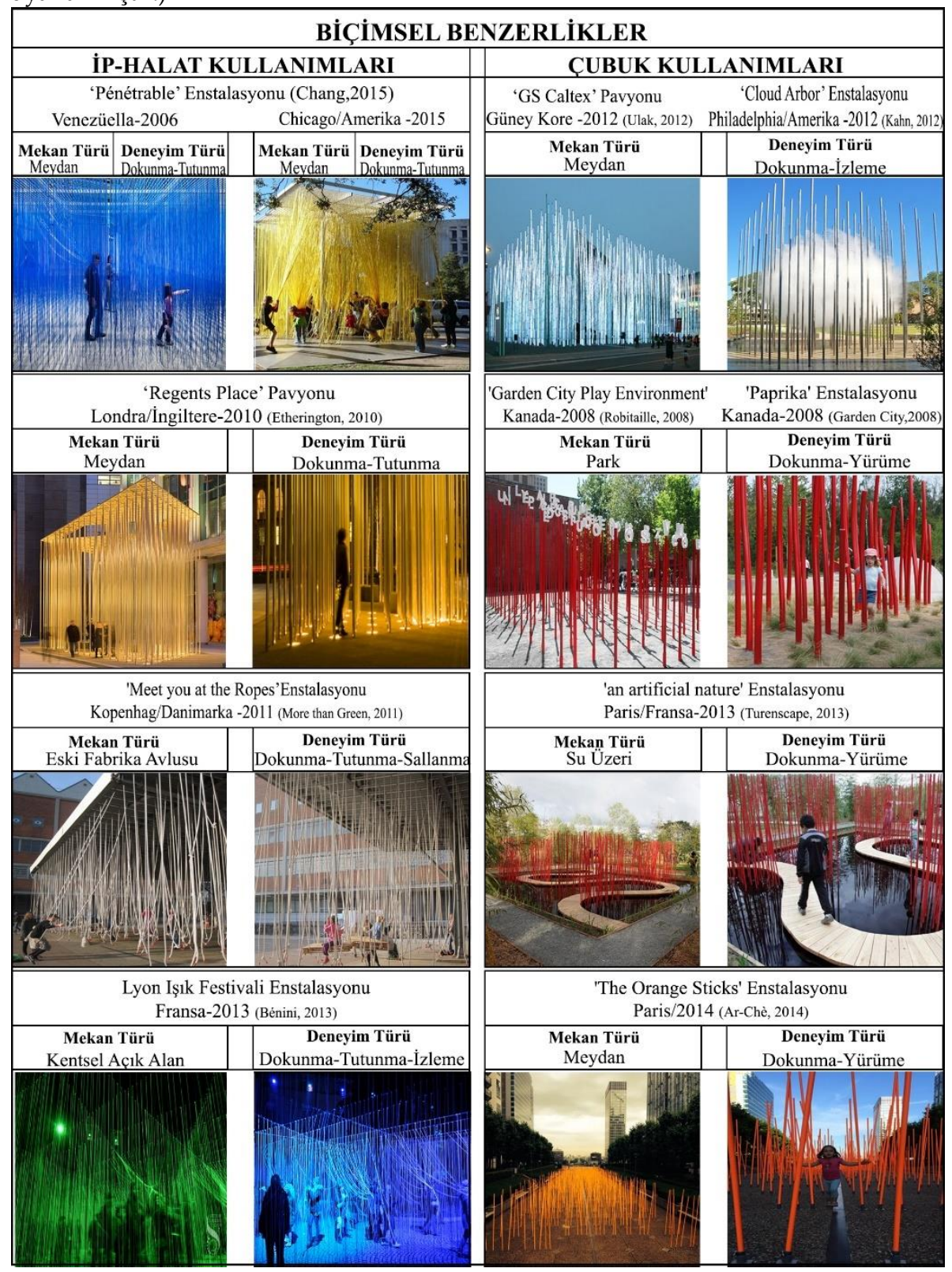


Tablo 2. Deneysel Kamusal Sanat Ürünlerinde Biçimsel Benzerlikler (Kılınç, 2020'den uyarlanmıştır.)

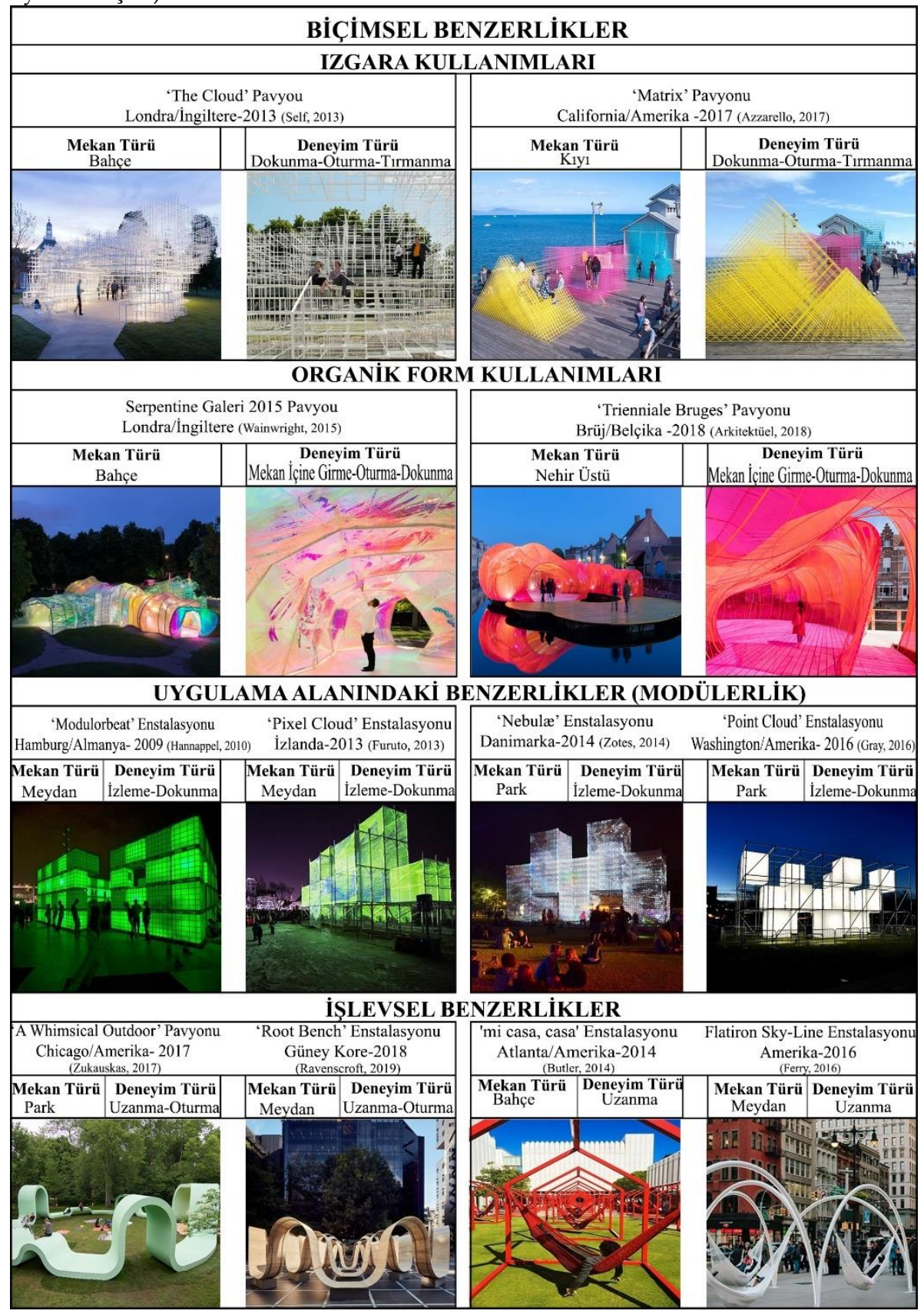


Tablo 3. Deneysel Kamusal Sanat Ürünlerinde Biçimsel-Uygulama-İşlevsel Benzerlikler (Kılınç, 2020'den uyarlanmıştır.)

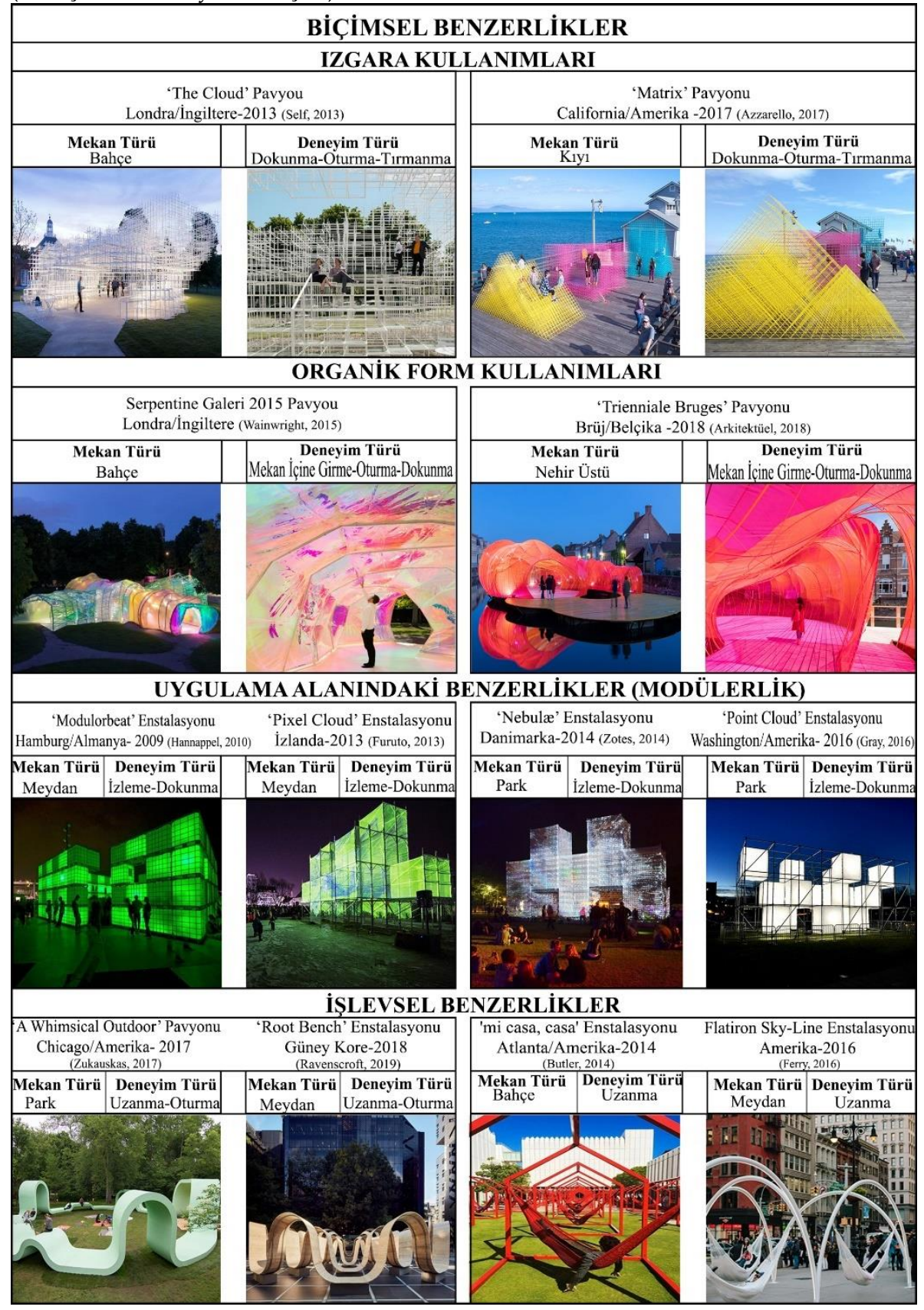


Çalışma için oluşturulan tablolardaki örneklerle enstalasyon ve pavyon sayılarındaki artış ifade edilmek istenmiş ve bununla birlikte verilen örneklerde biçimsel, işlevsel ve uygulama alanlarındaki benzerliklere dikkat çekilmek istenmiştir. Sayıların bu denli artmasının tek sebebi üretici nüfusun artması değildir. Bienaller, fuarlar, galeriler, çeşitli etkinlikler için yapılan ürünler, genç mimarların 'MoMA' gibi müzelerde açılan yarışmalarda adlarını duyurabilmek için yaptıkları tasarımlar ve koleksiyonerlerin kişisel olarak almak için sıraya girdikleri ürünler; bütün bunlar enstalasyon pavyon gibi kamusal sanat ürünlerinin saylsını arttırmakta üstelik bu durumu bir rekabet ortamına dönüştürmektedir. $\mathrm{Bu}$ durum enstalasyon ve pavyonların deneysel bir uygulamadan ziyade 'ün' kazanılmaya çalışılan bir 'sıçrama tahtası' olarak görülmesine neden olmaktadır (K1lınç, 2020). Sanat ve tasarım dünyasındaki bu yükselme ve sıçrama gayretleri fazla üretime neden olup sanatı deneysellik bağlamından uzaklaştırmaktadır. Sanatın içinde bulunduğu bu uzaklaşma tavrı ile ilişkili olarak Lavin (2012), günümüzde enstalasyon ve pavyonların gösterişli ve göz kamaştırıc örnekleri olduğunu fakat büyük bir kısmının kültür, yer, bağlam ve gelenek ile ilgili olmadığını, bu ürünlerin projeden ziyade 'parti dekoruna düştügü̈'nü ifade etmiştir. Tablolardaki örnekler birbirinden farklı konum ve ölçeklerde yer almakta, bireylere sunduğu deneyim şekli de ürünün tasarımına göre ayrışabilmektedir. Kamusal sanat ürünlerinin konumlandığı mekâna göre tasarımın bireylere sunduğu deneyimler dokunma, yürüme, oturma, bakıp geçme, izleme, tırmanma, mekânın içine girme, tutunma şeklinde değişkenlik göstermektedir. İşlevsel benzerliklerin irdelendiği tabloda mekânların farklılaştığı ancak deneyim türünün oturma ve uzanma biçiminde kısıtlı kaldığı ve çeşitlenemediği görülmüştür. Biçimsel ve uygulama alanındaki benzerliklerin incelendiği tablolarda orijinalliğini kaybeden ürünlerin birbirinin benzeri şekilde dünyanın bütün coğrafyalarına, kültürlerine, iklimlerine aynı biçimde entegre edilmeye çalışıldığı görülmüş̧ür. Dolayısıyla bu durum her mekân, her birey için ayrışamayarak ayn deneyim kavramının oluşmasına sebep olmaktadır. Bu noktada sorgulanması gereken sanatın bağlam, kültür, gelenek gibi faktörleri içinde barındırma zorunluluğuna sahip olması değil, hemen hemen aynı sayılabilecek çoğu ürünün herhangi bir 'aitlik' hissiyatı barındırmadan dünyadaki pek çok yere aynı şekilde bütünleştirilmeye çalışılmasıdır. Bu doğrultuda sergilenen tasarımların ölçek ve mekânları değişkenlik gösterdiği halde gittikçe birbirlerine benzemesi durumu, mevcut sürecin bir sonucu olarak değerlendirilebilir. Sergilenen tasarımların sayılarının çoğalması ile gelen benzerlikler kamusal sanatta tekdüze, tek tipleşen, standartlaşan ve prototipleşen ifa- 
delere sebep olmaktadır. Dolayısıyla kamusal sanat ürünlerinin mevcut durumda sürekli olarak kendini tekrar etmesi onun öncü, özgün, deneysel tavrına mesafe koymakta ve bu durum, sanatı 'üretilen' nesneden 'tüketilen' nesneye dönüştürmeye başlamıştır.

\section{Salgın Döneminde Kamusal Sanat}

İlk olarak 2019 yılında Çin'in Wuhan kentinde ortaya çıkan Covid-19 virüs salgını, tüm dünyada pandemiye neden olarak bireylerin fiziksel temasin azaltılması ve zaruri ihtiyaçlar dışında evde kalma mecburiyeti teşkil etmesinden ötürü kentsel açık alanların ıssızlaşmasına neden olmuştur. Salgının ilerlemesi ile 'evde kal'manın kimi zaman bireysel olarak alınan kararlarla, kimi zamansa yetkili kurumlarca uygulanan yasaklarla zorunluluğa dönüşmesi durumu, kamusal alanlarda bireylerin yakın mesafede olduğu kamusal sanat etkinliklerine ara vermiş̧ir. Bu ara, içinde bulunduğumuz salgın döneminde kamusal sanatın sunulma, sergilenme ve izlenme sürecinin dönüşümüne yol açmaya başlamıştır. Salgın ile 'evde kal' mottolarının yaygınlaşması kamusal alanda, kamusal sanat icraatını minimuma indirmekle beraber fiziksel olarak bir mekânda bir sanat ürününün deneyimlenmesi durumunu da zorlaştırmıştır. Fiziksel mekandaki bu kısıtlamalar dünyadaki diğer birçok kurum gibi sanat ve kültürle bağlarımızı nasıl yeniden tanımlayacağımızın sorgulanmasına sebep olmuştur (Tallant, 2020) (Merritt, 2020) Bu durum yer, mekân, kültür ilişkilerinden uzak bir yerde konumlanan ve herhangi bir bağlama ait olmayan dijital sanatı bu süreçte daha ön plana çıkarmıştır. Bireyin akıllı telefonlar, bilgisayarlar aracıllğıyla bulunduğu yerde herhangi bir fiziksel temas kurmadan bir sanat ürününü deneyimleyebilmesi, sanatın mevcut durumda koşullara göre dönüşebildiğini göstermiştir.

Salgın sürecinde günlük hareket rutini salt yaşam zorunluluklarını yerine getirmekle sınırlı olan bireyin, herhangi bir kamusal mekânda tesadüfen karşılaşacağı kamusal sanat olasılığının düşük olması, sanatın yapılma biçimlerini de değiştirmeye başlamıştır. Zaman ve mekândan bağımsız olarak herhangi bir yere gitmeyi gerektirmeyen dijital sanat etkinlikleri, sosyal mesafenin önem teşkil ettiği bu dönemde teknolojinin sanat üzerindeki geçerliliğini ortaya çıkarmıştır. Birçok müze pandemiden önce dijital olarak ziyaret edilebilse de pandeminin eve kapanma dönemlerinde dijital faaliyetlerini geliştirip hizmete açarak 'duvarsız müzelerin (Vajda, 2020) sayılarını artırmışlardır. Müzeler geçirdikleri dönüşüme bağlı olarak online tiyatro gösterileri, online galeri gezintileri, online resim, heykel sergileri şeklinde çeşitlenerek bu süreçte sanatın yapılma biçimlerini de değiştirmeye başlamıştır. Salgın dönemi 
ile mevcutta var olan müzelerin sanal sanat turlarının sayısı artmış, bireyler evlerinden sanat galerilerinin çevrimiçi etkinliklerine katılmaya başlamışlardır (Surface Impression, t.y.), (Moving Exhibitions Online: Solutions for Galleries in Lockdown, t.y.), (Google Arts and Culture t.y.).

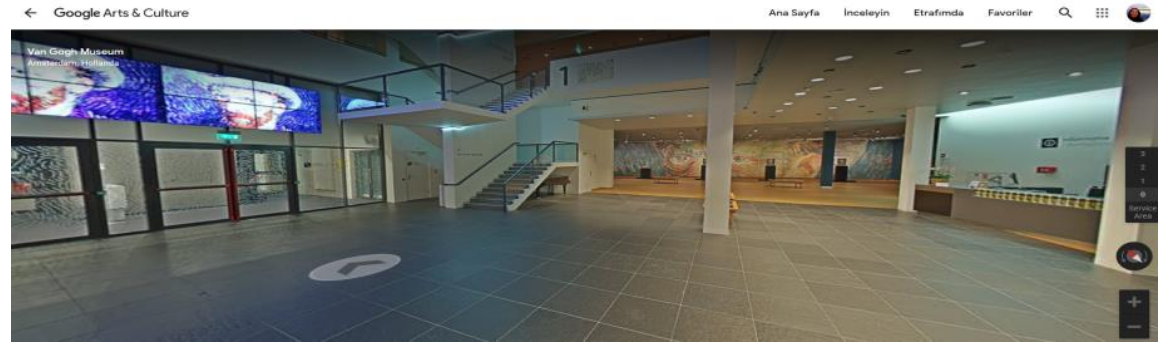

Şekil 1. Van Gogh Müzesi-Hollanda Sanal Tur (Google Arts and Culture, t.y.)

Süreç içerisinde sanal tur etkinliklerine katılma oranının yükselmesinde sosyal medya oldukça etkili olmuştur (ICOM , 2020) (Interreg Europe , 2020). Oluşan yeni müze formları, çevrimiçi etkinlikler ve sergiler ziyaretçi sayısını artırma çabası doğrultusunda hazırlanan içerikler dijital kamusal sanatı tüketim kültürüne katması açısından dikkat çekici olmaya başlamıştır. 'Evde kalma' süresince dijital sergiler hızla sayılarını artırmış ve kamusal sanatı dijital bir tüketim kültürüne dahil etmeye başlamışlardır. Farklı arayüzlere sahip olan dijital sergiler kullanıcılara kimi zaman müze mekânını ve sergilenen ürünü daha iyi tanıtmaya çalışmış kimi zaman da bu konuda yetersiz kalmıştır. Kimi müzeler plan, aksonometrik düzlem, üç boyutta hareket edebilme, görsel, sesli, videolu destekler ve rehber gibi çok daha detaylı seçenekler sunarken kimi müzeler sadece kullanıciya üç boyutta hareket etme seçeneği sunmuştur (Troya Müzesi Sanal Tur, T.C. Kültür ve Turizm Bakanlığı). Bu durum kullanıcıların dijital sürece ne kadar katılımcı olabileceğinin müzelerin içerikleri tarafından belirlendiğini göstermiş, iletişim ve etkileşimin ziyaretçi katılım düzeyini etkilediğini ortaya koymuştur. Bununla beraber yaşanılan süreç sanatın dijital bir şekilde devamlılığının sağlanabileceğini göstermektedir. 


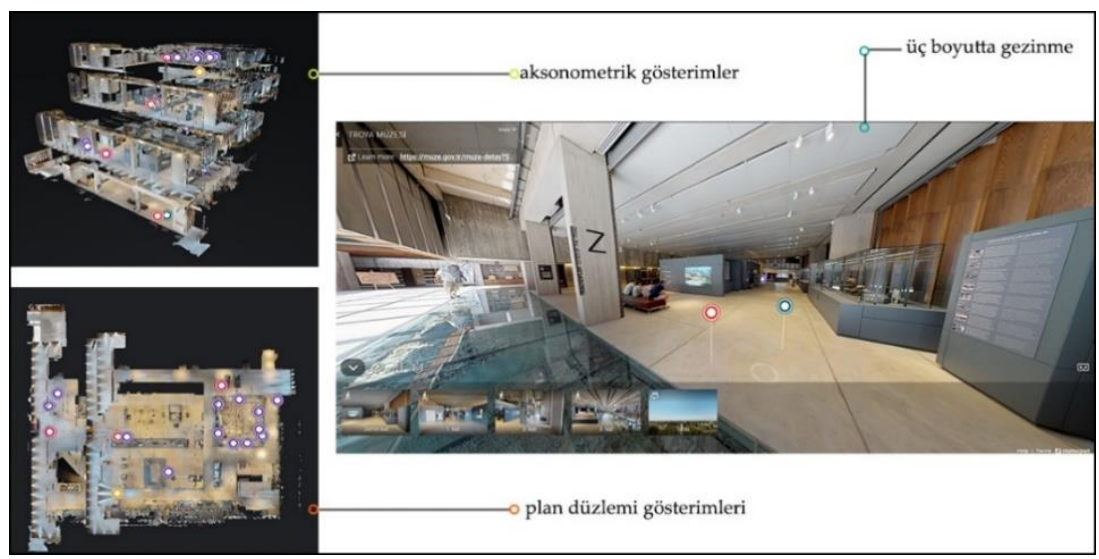

Şekil 2. Troya Müzesi-Türkiye Sanal Tur (Troya Müzesi, t. y.)

Sanatın evlerdeki webcam'ler üzerinden dijitalleşmesi aynı zamanda temassız deneyimleri ortaya çıarmaya başlamıştır. Sanat ürününün bir mekâna ait olma durumundan sanal bir ekranda boşlukta yer edinmeye evrilmesi, VR teknolojiler hariç çoğunlukla iki boyutta algılanabilmesi, dokunulmadan, mekânla olan ilişkisinin hissedilmeden deneyimlenmeye çalışılması bu süreci tartışmalı bir noktaya getirmektedir. İçinde bulunulan bu şartlarsa fiziksel temasa maruz kalmadan sanatın tam anlamiyla deneyimlenip deneyimlenmediği sorunsalını açığa çıkarmaktadır. Sanal sanat etkinliklerinin yapılması kimi kaynaklarca fiziksel temasa geçilemeyen internet ortamının sanat kuruluşları için cezalandırıı olduğuna dair çıkarımlar yapılmış ve sanatın çoğu insan için öncelik olmaktan çıktığına dair çeşitli anket raporları hazırlanmıştır (Feldman, 2020). Amerika' da 124.000 kişi üzerinden yapılan ankette halkın sosyal mesafenin sona ermesinden ardından sabırsızlıkla beklediği etkinlikler arasında en popüler olanı "sevdiklerimizle evlerimizde bir araya gelmek" yüzde 70 olmuştur. Bireylerin yapmak istedikleri etkinliğe dair sorunun yanttında ise yüzde 59 'ü bir bara ya da restorana gitmeye hevesliyken, yüzde 32'si kanepeden kalkıp sinemaya tekrar gitmek için heyecanlandığını, sadece yüzde 9'u bir sanat müzesine gitmeyi düşündüğünü ifade etmiştir (Davis, 2020). Mevcut koşullarda sanatın önceliklerden çıkmasındaki en büyük nedense salgın döneminde daha acil ihtiyaçların öne çımasıdır. Sağlıklı olma, insanların sevdikleri ile bir arada olma isteği kamusal sanat bu sıralamada arka sıralara itmiştir. Dolayısıyla belli maddi desteklerle gerçekleştirilen sanat etkinliklerine yapılan yardımlarsa yerini hayır kurumlarına yapılan yardımlara bırakmaya başlamıştır (Billock, 2020). Bütün bu verilerden sonra ise kamusal sanatın salgın sonrası dönüşerek konumunun başka bir noktaya evrileceği öngörülmektedir. 


\section{Tartışma ve Sonuç}

Modern kültürel sanatın disiplinler arası üretimi olarak deneysel kamusal sanat ürünleri farklı pratiklerin sanatla olan iş birliği ile bireyleri katılımcılığa teşvik etmesi ve kullanıcılara deneyim arzuların yaşatma firsatı vermesi bakımından oldukça önemlidir. Disiplinler arası bu süreçte enstalasyon ve pavyonlar tasarımcılara görüp-öğrenme firsatı vererek aslında bir nevi deney imkânı sağlamaktadır. Bu ürünlerin üstlendiği rol teknolojinin ilerlemesiyle 21. yüzyılda sınırlarını geliştirip, genişletmiştir. Dijital ve sanal gerçekliğin günlük hayatta daha çok yer alması sanata da etki etmiştir. Bu doğrultuda yeni medya araçlarının kullanımı sanatın ifadesinde değişiklikler oluşturarak deneysellik bakımından katkıda bulunmuştur. Gerçekliğin farklı kurgu yüzeylerle kent mekânının parçası olma durumu sanat ile teknolojinin entegrasyonunu sağlamış kentlere potansiyel kazandırmış ve kazandırmaktadır (Kılınç, 2020). Bu bakımdan kamusal sanatın 21. yüzylldaki durumu değerli olmakla beraber dünyanın çeşitli yerlerinde sergilenen enstalasyon ve pavyonların çok fazla sayıda üretilmesinin beraberinde getirdiği durum da tartışlır hale gelmektedir.

21. yüzyılda deneysel kamusal sanat ürünlerinin sayılarının bu denli artmasının sebeplerinden biri teknolojinin gelişmesiyle sanat ürünlerine olan erişilebilirlik ve ulaşılabilirliğin artmasıdır. Bu durum ise bu ürünlerin yapılabilirliğini kolaylaştırmıştır. Bir başka sebep ise kamusal sanatın uygulama açısından disiplinler arası olma durumudur. Farklı pratiklere mensup mimar, sanatçı, heykeltıraş, ressamlar üretici nüfusu arttırmakta ve bu durumda kamusal sanat ürünlerinin sayılarında artışa neden olmaktadır.

Süreç içerisinde pavyon ve enstalasyonların kendini tekrarı konusu üretilen tasarımlara da başka bir boyut katmaktadır. Biçimsel, işlevsel, uygulama alanındaki özellikleri bakımından irdelenen kamusal sanat ürünlerinde tasarımların yalnızca aynı fikrin ayrı malzeme, renk ya da kullanılan bir aparatla farklılaşmaya çalışmaktan öteye gidemediği gözlemlenmiştir. Bu perspektiften bakıldığında mevcut süreçte üretilen pavyon ve enstalasyonların fikir altyapılarının çok büyük oranda aynı kurguyu barındırması ortaya çıkan içeriklerinde benzer boyutta kalmasına neden olmuştur. Farklı bir ifadeyle kamusal sanatı üreten nüfus ve ortaya çıkan tasarımlar, kendini tekrar edip aslında tüketmeye başlamıştır. Bu tüketim hali ise aslında sanatın güncel tavrının deneysellikle olan ilişkisi bakımından çelişkilidir. Bu çelişki “Deneysel olan tekrarlanamaz deneysel olan 'özel ve biricik'tir (Hannula, 2007)" fikri üzerinden irdelendiğinde aslında tekrarlanarak prototipleşen ürünlerin değersizleştiği 
ve deneysellikten uzaklaşttğg düşünülmektedir. Günümüzde benzer kamusal sanat ürünleri dünyadaki dünyanın herhangi bir konumunda farklı mekân türlerinde sergileniyor olsa da yalnızca 'benzersiz' olan orijinal üründe deneysellikten söz edilebilir. Sanatın, deneysel üründen esinlenen işlevsel, biçimsel ya da uygulama olarak kopyalanabilmesi durumu, orijinal 'deneysel kamusal sanat' ürününün deneyselliğinin de tekrarlanacağı anlamına gelmez. Bu bağlamda sanat ürünleri tekrarlandıkça deneyselliklerini yitirmekte ve aslında yalnızca 'kamusal sanat' işlevini yerine getirmektedir. $\mathrm{Bu}$ durum, özgün olmayan kamusal sanatı daha az nitelikli hale getirmektedir. Kamusal sanatın niteliğinin düşmesi ile ilgili olarak, medyanın bu durumun ortaya çıkmasında büyük etkisi vardır. Medyadaki bazı sanat ürünleri hakkında daha fazla haber, tanıtım yapılması, bazı sanat ürünlerinin medyada daha az yer alması veya hiç yer almaması, tasarımcıları bu yönde şekillendirmektedir. Tasarımcılar 'doğru' varsaydıkları ürünleri daha çok üreterek kamusal sanatın tek tipleşmesine sebebiyet vermektedirler. Bilimsel olmaktan uzak bu tür yaklaşımlarda, tek tipleşme temeli, günlük yaşamdaki popülerlik anlayışı üzerinden oluşturulmaktadır. 21. yüzyılla birlikte sosyal çevrenin ve teknolojinin gelişmesiyle birlikte sanatın kamusal mekânda rahatlıkla uygulanabildiği, daha çok insanla buluştuğu ve deneyimlendiği durum her zaman özeldir. Ancak 21. yüzyılda, her üründe olmasa da çoğu kamusal sanat ürününün orijinal olamaması, kendini tekrar etmesi ve tekilleşememesi kamusal sanat ile deneysellik arasına mesafe koymakta ve sanatı temsil ettiği değerleri açısından başkalaştırmaktadır.

Salgın döneminde ise en genel anlamda kamusal alana kamusal sanat aracılığyyla yapılan müdahalelerin dönüşümü söz konusu olmuştur. Kamusal alanın tanımının, kamusal alanda sanat aracilığıyla oluşturulan bir arada olma biçimlerinin değişip yeniden sorgulandığı bu süreçte yeni olasılıkların oluşabileceği görülmüştür. Salgının ortaya çıkardığı yeni koşullara sanatı uyarlayan dijital öneriler her ne kadar sanatın sürdürülebilirliğini devam ettirmeye çalışsa da sanatın mekândan bağımsız olma hali de tartışmalıdır. Herhangi bir yere, kültüre, coğrafyaya kısacası bir bağlama ait olamayan sanatın dijital sanata kayma hali ise tıpkı salgından önceki sanatın tek tipleşmesi süreci gibi bu dönemi de tüketim kültürüne bağlı kılarak tek tipleştirebilir. Dijital içeriklerin sayılarının arttığı bu dönemde sadece dijitallik konusunun değil bu dijitalliğin içerik olarak mekânsal ve sanatsal anlamda kullanıcılara neler sunduğu-sunabileceği de tartışmaya açlmalıdır 


\title{
Extended Abstract
}

\section{Experimental Public Art in the 21st Century}

\author{
Cemre Kilınç ${ }^{1}$ \\ Osman Tutal ${ }^{2}$ \\ ORCID: 0000-0001-8651-6945 \\ ORCID: 0000-0003-1454-5514
}

Public spaces that host life in urban spaces are among the most important elements that make cities livable with their unique historical, cultural or geographical features and characteristics. These interaction spaces, which have an important place in the memory of cities, pass through the idea of public art in public spaces (Mitrache, 2012). In its simplest form, public art can be defined as art that can be easily seen by the society, accessible and generally done in public space (Hayden, 1995). Public art enables the individual to rediscover a familiar place and develop new perceptions.

Experimental public art products such as pavilions and installations, which are interdisciplinary productions that we have started to see frequently since the beginning of the 21st century, attract attention with the vitality, dynamism and aesthetics they bring to the space. Although it cannot be seen in person, almost every day, it is seen in articles, magazines, websites, architectural media or social media that experimental public art products such as installations and pavilions are exhibited. It is extremely valuable that public art has a greater place in our lives in the 2000s and that it is exhibited in different geographical regions and cities of the world. In this respect, the positive aspects that art provides to the individual, the city and the space cannot be ignored. However, the fact that the number of experimental public art products has increased so much has started to attract attention. So much so that these products, which have started to find a place for themselves on the world stage in the last twenty years, are "Pavilions are everywhere." (Lavin, 2012) is also reflected in discourses. The proliferation of practices that come with this 'everywhere' situation has led to an increase in similarities in public art products. Increasing similarities, on the other hand, bring with it the question of where the parameters of experimentexperimentation are in public art products such as pavilions and installations. 
This approach, on the other hand, causes the repetition of similar public art products and transforms them into "replicated prototypes (Güzer, 2019)". This prototyping, on the other hand, distracts art from its experimentalist attitude. Today public art practices with similar characteristics, which are frequently encountered in the media and social media, create the impression of 'what should be in art' with the idea of 'up-to-date', and by directing the designers, it creates the impression that these products are accepted.

The biggest reason for such an increase in the number of public art products is the increase in the productive population. However, biennials, fairs, galleries, products made for various events, products that collectors line up to buy personally; all this increases the number of public art products such as the installation pavilion, and turns this situation into a competitive environment. The similarities that come with the increase in the number of the designs exhibited cause uniform, uniform, standardized and prototypical expressions in public art (Figure 1-2-3). Therefore, the constant repetition of public art products in the current situation distances the pioneering, original and experimental attitude of art, and this situation has begun to transform art from an 'produced' object to a 'consumed' object.

In the period of the Covid-19 pandemic, the situation that 'lockdown' turned into a necessity, sometimes with individual decisions and sometimes with bans imposed by authorized institutions, interrupted public art activities in public spaces where individuals were at close range. At this time, during the pandemic period in which we are in, it has begun to deconstruct the process of presentation, exhibition and viewing of public art. With the pandemic, the spread of' stay at home ' mottos in the public space has minimized the performance of public art but has also made it difficult to physically experience a product of art in a public space. These restrictions on physical space, like many other institutions around the world, have led to the question of how to redefine our ties to art and culture (Tallant, 2020). This situation has brought digital art to the fore in this process, which is located away from place, space and cultural relations and does not belong to any context. The fact that an individual can experience an art product without any physical contact through smartphones and computers has shown that art can transform according to the conditions in the current situation. In the process, social media has been very effective in increasing the rate of participation in virtual tour activities (ICOM , 2020). The new museum forms, online events and exhibitions, which are prepared in line with the effort to increase the number of visitors, have started to attract attention in terms of adding digital public art to the consumption culture. 
As a result, while the status of public art in the 21st century is valuable, the situation brought about by the large number of installations and pavilions exhibited in various parts of the world becomes debatable. The population producing public art and the emerging designs have increasingly begun to repeat themselves and actually consume them. This consumption state is actually contradictory in terms of the relationship between the contemporary attitude of art and experimentality. When this contradiction is examined through the idea that "the experimental is the unrepeatable and the experimental one is special and unique (Hannula, 2007)" it is thought that the products that have been prototypicalized by repetition become worthless and move away from experimentalism. In the Covid-19 period, although digital proposals that adapt art to current conditions try to maintain the sustainability of art, the fact that art is independent of space is also considered controversial. The shift of art that does not belong to any context to digital art can standardize this period by making it dependent on consumption culture, just like the process of standardization of art before the pandemic. In this direction, what digital art can offer users as content should also be questioned, and it is important to do work in this direction.

\section{Kaynakça/References}

Altenburger, E. (t. y.). Mirror house. tinyBe.com. Erişim adresi: https://tinybe.org/en/impulses/

Ar-Chè, A. (2014). La praire. divisare.com. Erişim adresi: https://divisare.com/projects/265596-atelier-Ar-Ch-Ch-rifa-S-himi-J-r-meGirard-La-Prairie

Arkitektüel. (2018). Yll biterken: 2018'in En dikkat çeken 10 pavyon tasarımı. Arkitektüel. Erişim adresi: https://www.arkitektuel.com/yil-biterken-2018in-en-dikkat-ceken-10-pavyon-tasarimi/

Aydın, R. E. (2015). "Kamusal Alan ve Sanat" konusuna eleştirel bir yaklaşım. Erişim adresi: https://ronyaemel.wordpress.com/: https://ronyaemel.wordpress.com/2015/04/07/kamusal-alan-ve-sanatkonusuna-elestirel-bir-yaklasim/

Azzarello, N. (2017). Phillip K. Smith III's 'Circle of land and sky' Mirrors abstract views of the California desert. designboom.com. Erişim adresi: https://www.designboom.com/art/phillip-k-smith-iii-desert-x-the-circleof-land-and-sky-california-palm-desert-03-02-2017/

Azzarello, N. (2017). Rainbow-hued light labyrinth by brut deluxe forms an immersive infinity room in China. designboom.com. Erişim adresi: https://www.designboom.com/art/brut-deluxe-yuzhou-immersive-lightlabyrinth-china-01-16-2017/ 
Azzarello, N. (2017). Sports punctuates the city of santa barbara with colorful matrix pavilions. designboom.com. Erişim adresi: https:/www.designboom.com/design/sports-collective-santa-barbararunaway-04-30-2017/

Bénini, A. (2013). Climatic caresse. Fete des lumieres. Erişim adresi: https://www.fetedeslumieres.lyon.fr/en/installation/caresses-climatiques

Billock, J. (2020). How street artists around the world are reacting to life with covid-19. Smithsonian.

Bourdieu, P. (1984). Distinction: A social critique of the judgement of taste. London $\mathcal{E}$ New York: Routledge.

Butler, A. (2014). Mi casa, your casa by hector esrawe and ignacio cadena. designboom.com. Erişim adresi: https://www.designboom.com/design/mi-casa-your-casa-by-hectoresrawe-and-ignacio-cadena-11-21-

2014/?utm_campaign=daily\&utm_medium=email\&utm_source=subscribers

Caula, R. (2012). Mud brick and mirror spiral installation. designboom.com. Erişim adresi: https://www.designboom.com/art/mud-brick-and-mirrorspiral-installation-by-elin-hansdottir/

Chang, D. (2015). Pénétrable in Chicago I Jesús Rafael Soto. arch20.com. Erişim adresi: https://www.arch2o.com/p\%c3\%a9n\%c3\%a9trable-in-chicagojes\%c3\%bas-rafael-soto/

Davis, B. (2020). What does the public want from art in a post-covid world? Here are 5 takeaways from a massive new study. artnet.com. Erişim adresi: https://news.artnet.com/art-world/culture-community-in-a-time-of-crisis1892897

Ercan, M. (2013, Eylül). Kamusal sanatın 'Kamusallığı': Erişim, aktör, fayda yaklaşımı. İdealkent Dergisi, 4(10), 220-255.

Etherington, R. (2010). Regent's place pavilion by carmody groarke. dezeen.com. Erişim adresi: https://www.dezeen.com/2010/01/28/regents-placepavilion-by-carmody-groarke/ adresinden alındı

Ferry, B. W. (2016). Flatiron sky-line by lot, New York. urdesign.com. Erişim adresi: https:/www.urdesignmag.com/design/2016/12/21/flatiron-skyline-lot-new-york/

Furuto, A. (2013). Pixel cloud installation / Ustable. Archdaily.com. Erişim adresi: https://www.archdaily.com/356993/pixel-cloud-installationunstable?ad_medium=gallery

Feldman, K. (2020). Leading the national gallery of art during covid-19. Museum Management and Curatorship.

Garden City Play Environment. (2008). architizer.com. Erişim adresi: https://architizer.com/projects/garden-city-play-environment/ 
Goldberg, M. (2019). Softlab's mirror mirror installation opens at Alexandria's revamped waterfront. Archinet News. Erişim adresi: https://archinect.com/news/article/150129579/softlab-s-mirror-mirrorinstallation-opens-at-alexandria-s-revamped-waterfront

Google Arts ad Culture. (t. y.). Erişim adresi: https://artsandculture.google.com/streetview/deutsches-museum-minemodern-

mining/cgGPCk6Il1u0xg?sv_lng=11.58322817397539\&sv_lat=48.129340777 $26873 \& s v \_h=105.35701269625716 \& s v \_p=-$

22.943624405689135\&sv_pid=UbWqEXEU3pUAAAQvPCeukg\&sv_z=1 Google Arts and Culture. (t. y.). Erişim adresi: https://artsandculture.google.com/streetview/rezan-has-museum-google arts-culture-

team/JgEwdy1Y61Y6rw?sv_lng=28.95887657800867\&sv_lat=41.0254775366 1164\&sv_h=197\&sv_p=0\&sv_pid=NOslgLUuD8DRID9cN1XQ0A\&sv_z=1

Gökmen, L. (2016, July 1). Konutta proje ligi. Ekonomist. Erişim adresi: http://www.ekonomist.com.tr/kapak-konusu/konutta-proje-ligi.html

Gray, B. (2016). Point cloud at the yards park. Urban Bohemian. Erişim adresi: https://urbanbohemian.com/2016/02/25/point-cloud-the-yards-park/

Güzer, C. A. (2019, Eylül 15). Mimari tasarım, sanat ve eleştiri. (Ö. Yalım, Röportaj Yapan) T24 Haftalı Gazetesi. İstanbul.

Habermas, J. (1962). Kamusallı̆ın yapısal dönüşümü: Burjuva toplumunun bir kategorisi üzerine araştırmalar. (T. Bora, \& M. Sancar, Çev.) İstanbul: İletişim Yayıncılık.

Hannappel, W. (2010). Lichtinstallationen für "ruhrlights: twilight zone internationale lichtkunst an der ruhr". modulorbeat. Erişim adresi: https://www.modulorbeat.de/work/untitled

Hannula, M. (2007). Karşılıklı ilişki ve yeryüzünde olmaya dair. S. B. Pelin Tan (Dü.) içinde, Olasılıklar, Duruşlar, Müzakere Güncel Sanatta Kamusal Alan Tartışmaları, 58. İstanbul: Bilgi Üniversitesi Yayınları.

Hanru, H. (2007). Sürekli yenilenen kamusallığı kurmak ve kolektif eylem. Olasılıklar, Duruşlar, Müzakere Güncel Sanatta Kamusal Alan Tartışmaları, 139-142. (P. Tan, Röportaj Yapan, \& E. Kosova, Çevirmen) İstanbul: Bilgi Üniversitesi Yayınları.

Hayden, D. (1995). The power of place: Urban landscapes as public history. Cambridge Massachusetts, London: The Mit Press.

ICOM . (2020). Museums and the covid-19 crisis: 8 Steps to supporting community resilience. Internatioanl Council of Museums.

Interreg Europe. (2020). Digital technologies and museums: post-pandemic experiences. Policy Learning Platform.

Kahn, N. (2012). Cloud arbor. institute for public art. Erişim adresi: https://www.instituteforpublicart.org/case-studies/cloud-arbor/

Kejanlıoğlu, B. (2004). Medya çalışmalarında kamusal alan kavramı. M. Özbek (Dü.) içinde, Kamusal Alan, 699-700. Hil Yayın. 
Kılınç, C. (2020). Kamusal sanatın deneyselliği üzerine bir irdeleme. (Yüksek Lisans Tezi). Ulusal Tez Merkezi veri tabanından erişildi.

Krzykowski, M. (2008). Cityscope by Marco Hemmerling. dezeen. Erişim adresi: https://www.dezeen.com/2008/11/24/cityscope-by-marco-hemmerling/

Lavin, S. (2012). Vanishing point: The contemporary pavilion. Artforum International, 51(2).

Merritt, E. (2020). Reinventing museums: pandemic disruption as an opportunity for change. American Alliance of Museums.

Mitrache, G. (2012). Architecture, art, public space. (A. Ç. İlhan, Dü.) Procedia Social and Behavioral Sciences(51), s. 562-566. Erişim adresi: https://www.sciencedirect.com/science/article/pii/S1877042812033447

More than Green. (2011). The rope show I A playful urban installation made of ropes I Copenhagen. Erişim adresi: http://www.morethangreen.es/en/therope-show-a-playful-urban-installation-made-of-ropes-in-copenhagen/

Moving exhibitions online: solutions for galleries in lockdown. (t. y.). Surface impression. Erişim adresi: https://surfaceimpression.digital/onlineexhibitions/

Murray, J. (1900). Murray's hand-book constantinople Brusa, and the Throad. London: John Murray.

Phillips, P. C. (1999). Dynamic exchange public art at this time. Public Art Review(11), 49.

Pintos, P. (2019). Ziggy installation / Hou de Sousa. Archdaily: https://www.archdaily.com/929993/ziggy-installation-hou-de-sousa

Ravenscroft, T. (2019). Paul Cocksedge creates undulating communal bench in London. dezeen.com. Erişim adresi: https://www.dezeen.com/2019/09/18/paul-cocksedge-please-be-seatedfurniture-london/

Robitaille, D. (2008). Amherst Park anamorphic installation. commarts.com. Erişim adresi: https://www.commarts.com/project/19919/amherst-parkanamorphic-installation

Roitman, S. (2010). Gated communities: definitions, causes and consequences. Urban Design and Planning, 163(1), 31-38.

Rojek, C. (2000). Indexing, dragging and the social construction of tourist sights. C. R. Urry içinde, Touring Cultures. Transformation of Travel and Theory, 52-74. New York: Routledge.

Self, J. (2013). L'armonia non è ovvia. domus. Erişim adresi: https://www.domusweb.it/it/architettura/2013/06/7/sou_fujimoto_serpenti ne_gallery.html

Sheikh, S. (2007). Kamusal alanın yerine ne mi? Ya da, parçalardan oluşan dünya. P. Tan, \& S. Boynik (Dü) içinde, Olasıliklar, Duruşlar, Müzakere Güncel Sanatta Kamusal Alan Tartışmaları. İstanbul: Bilgi Üniversitesi Yayınları. 
Sousa, J. d. (2018). Hou de Sousa's iridescent prismatic installation in georgetown frames a myriad of perspectives. designboom.com. Erişim adresi: https://www.designboom.com/architecture/hou-de-sousa-iridescentprismatic-installation-myriad-perspectives-12-10-2018/

Surface Impression. (t. y.). Erişim adresi: https://surfaceimpression.digital/onlineexhibitions/

Tallant, S. (2020). Rethinking museums for the future. The UNESCO Courier(3), 12-14.

Troya Müzesi. (t. y.). T.C. Kültür ve Turizm Bakanlığı. Erişim adresi: https://sanalmuze.gov.tr/TR-259960/troya-muzesi---canakkale.html

Turenscape. (2013). Square \& Round. contemporist.com. Erişim adresi: https://www.contemporist.com/square-round-by-turenscape/

Ulak, A. (2012). Atelier brückner: Gs caltex pavilion for the 2012 expo korea. designboom.com. Erişim adresi:

https://www.designboom.com/readers/atelier-bruckner-gs-caltexpavilion-for-the-2012-expo-korea/

Vajda, A. (2020). Museums and online spaces. The society building role of the museums during the pandemic. commUnicAtio(7), 42-53.

Wainwright, O. (2015). Serpentine pavilion 2015: a rainbow wormhole ready to suck you into another dimension. The Guardian. Erişim adresi: https://www.theguardian.com/artanddesign/2015/jun/22/serpentinepavilion-2015-a-rainbow-wormhole-ready-to-suck-you-into-anotherdimension

Wilde, A. d. (2017). Lighting, layers and reflections . DesignCollector. Erişim adresi: https://designcollector.net/likes/lighting-layers-and-reflections-byautumn-de-wilde

Yilmaz, Z. (2007). Hannah Arendt'te özel alan-kamusal alan ayrımı ve modern çağda toplumsal alan (Doktora Tezi). Ulusal Tez Merkezi veri tabanından erişildi.

Yırtıcı, H., Gürer, T., \& Yıldız , G. (1993). Deneysel mimarlık. Mimarlık Dergisi(255).

Yoo, A. (2013). Maze of mirrors mesmerizes visitors inside Sydney's Hyde Park. My Modern Met. Erişim adresi: https://mymodernmet.com/art-and-aboutsydney-field/

Yoo, A. (2015). Mirror labryinth, twisted park benches and disappearing rooms of water at Brooklyn Bridge Park. My Modern Met. Erişim adresi: https://mymodernmet.com/jeppe-hein-please-touch-the-art-brooklynbridge-park/

Yükselbaba, Ü. (2011). Kamusal alan modelleri ve bu modellerin bağlamları. Journal of Istanbul University Law Faculty, 66(2), s. 227 - 271. Erişim adresi: https://dergipark.org.tr/iuhfm/issue/9184/115001

Zotes, M. (2014). Nebulæ installation by unstable roskilde - Denmark. Retail Design Blog. Erişim adresi: 
https://retaildesignblog.net/2014/09/21/nebulae-installation-by-unstableroskilde-denmark/

Zukauskas, N. (2017). A whimsical outdoor pavilion graces an artist colony in Illinois. Contemporist. Erişim adresi: https://www.contemporist.com/whimsical-outdoor-pavilion-graces-anartist-colony-in-illinois/ 